\title{
Coronary lesion complexity in patients with heterozygous familial hypercholesterolemia hospitalized for acute myocardial infarction: data from the RICO survey
}

Hermann Yao ${ }^{1}$, Michel Farnier ${ }^{1}$, Laura Tribouillard ${ }^{1,2}$, Frédéric Chague $^{1}$, Philippe Brunel ${ }^{3}$, Maud Maza ${ }^{1}$, Damien Brunet ${ }^{3}$, Luc Rochette ${ }^{2}$, Florence Bichat ${ }^{1}$, Yves Cottin ${ }^{1}$ and Marianne Zeller ${ }^{2^{*}}$ (i)

\begin{abstract}
Background: Although patients with familial heterozygous hypercholesterolemia (FH) have a high risk of early myocardial infarction (MI), the coronary artery disease (CAD) burden in $\mathrm{FH}$ patients with acute $\mathrm{Ml}$ remains to be investigated.

Methods: The data for all consecutive patients hospitalized in 2012-2019 for an acute Ml and who underwent coronary angiography were collected from a multicenter database (RICO database). FH ( $n=120)$ was diagnosed using Dutch Lipid Clinic Network criteria (score $\geq 6$ ). We compared the angiographic features of Ml patients with and without FH (score $0-2)(n=234)$ after matching for age, sex, and diabetes (1:2).

Results: Although LDL-cholesterol was high (208 [174-239] mg/dl), less than half of FH patients had chronic statin treatment. When compared with non-FH patients, FH increased the extent of CAD (as assessed by SYNTAX score; $P=0.005)$, and was associated with more frequent multivessel disease $(P=0.004)$, multiple complex lesions $(P=$ 0.022 ) and significant stenosis location on left circumflex and right coronary arteries. Moreover, FH patients had more multiple lesions, with an increased rate of bifurcation lesions or calcifications ( $P=0.021$ and $P=0.036$, respectively). In multivariate analysis, LDL-cholesterol levels (OR 1.948; 95\% Cl 1.090-3.480, $P=0.024)$ remained an independent estimator of anatomical complexity of coronary lesions, in addition to age (OR $1.035 ; 95 \% \mathrm{Cl} 1.014-$ $1.057, P=0.001)$.

Conclusions: $\mathrm{FH}$ patients with acute MI had more severe CAD, characterized by complex anatomical features that are mainly dependent on the LDL-cholesterol burden. Our findings reinforce the need for more aggressive preventive strategies in these high-risk patients, and for intensive lipid-lowering therapy as secondary prevention.
\end{abstract}

Keywords: Familial hypercholesterolemia, Myocardial infarction, Complex coronary lesions, LDL cholesterol

* Correspondence: Marianne.zeller@u-bourgogne.fr

${ }^{2}$ PEC2, EA 7460, UFR Health Sciences, University of Bourgogne Franche Comté, Dijon, France

Full list of author information is available at the end of the article

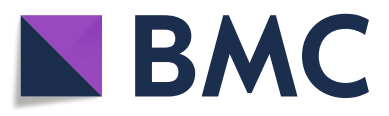

(c) The Author(s). 2021 Open Access This article is licensed under a Creative Commons Attribution 4.0 International License, which permits use, sharing, adaptation, distribution and reproduction in any medium or format, as long as you give appropriate credit to the original author(s) and the source, provide a link to the Creative Commons licence, and indicate if changes were made. The images or other third party material in this article are included in the article's Creative Commons licence, unless indicated otherwise in a credit line to the material. If material is not included in the article's Creative Commons licence and your intended use is not permitted by statutory regulation or exceeds the permitted use, you will need to obtain permission directly from the copyright holder. To view a copy of this licence, visit http://creativecommons.org/licenses/by/4.0/. The Creative Commons Public Domain Dedication waiver (http://creativecommons.org/publicdomain/zero/1.0/) applies to the data made available in this article, unless otherwise stated in a credit line to the data. 


\section{Introduction}

Heterozygous familial hypercholesterolemia (FH) is one of the most common autosomal dominant genetic diseases [1], with an estimated prevalence of $1 / 250$ in Western countries. It is characterized by high levels of LDL cholesterol (LDL-C) [2, 3], resulting in most cases from a mutation of the LDL receptor (LDL-R), apolipoprotein $B$ (apoB), or proprotein convertase subtilisin/kexin type 9 (PCSK9). The most commonly used routine diagnostic criteria are the Dutch Lipid Clinic Network (DLCN) criteria, based primarily on elevated LDL-C levels and the presence of a family and personal history of premature coronary heart disease [4]. In uncertain cases, a genetic analysis can be used to confirm the diagnosis and to provide sensitive and specific molecular family screening.

Patients with FH present a very high cardiovascular (CV) risk and are therefore exposed to the occurrence of coronary events at an early age $[5,6]$. On average, patients with $\mathrm{FH}$ have a risk of early coronary artery disease (CAD) that is 13 times higher than in the general population [5]. When individuals do not respond to treatment, fatal or non-fatal coronary events occur in approximately $50 \%$ of men $<50 y$ and $30 \%$ of women $<60$ y [6]. FH is often found after an individual has a myocardial infarction (MI), with an estimated prevalence between 1.6 and 4.3\% [7, 8]. Furthermore, FH patients have an unfavorable prognosis after MI, with a risk of recurrence of cardiovascular or coronary events that is 2 to 3 times higher than the average $[9,10]$. However, there are wide variations in the extent of CAD and in the level of coronary calcifications between individuals with genetically determined $\mathrm{FH}$, suggesting the need for a better understanding of its specificities $[4,11]$.

Thus, while the clinical course of these patients is relatively well known, there is a paucity of research focused on the associated coronary lesions. Although CAD is more frequently associated with multi-vessel disease in $\mathrm{FH}$ patients, there are significant variations in prevalence [12-14]. Using the Gensini angiographic score, Wang [8] and $\mathrm{Li}$ [15] showed that CAD was more severe in patients with $\mathrm{FH}$ than in those without $\mathrm{FH}$ (according to the DLCN criteria). Findings from a series of 104 asymptomatic age-matched patients found that coronary lesions in CAD patients with genetically confirmed heterozygous $\mathrm{FH}$ are more diffuse and calcified than in patients without a genetic mutation [16]. The angiographic characteristics of the anatomical complexity of coronary lesions, such as number, size, lesion length, and multiple lesions are risk factors that worsen prognosis after MI [17, 18]. In addition, targeted therapeutic strategies appear to be more beneficial in patients with complex coronary anatomy [19]. However, the complexity of coronary lesions in symptomatic patients with $\mathrm{FH}$ has not yet been described.
The objective of this study was therefore to characterize the severity and complexity of coronary lesions on coronary angiography in FH patients hospitalized for acute MI.

\section{Patients and methods \\ Study population, selection criteria}

This retrospective study was conducted using data from the RICO (Côte d'Or Myocardial Infarction Observatory) database [20]. RICO is an ongoing survey that has included all consecutive patients aged at least 18 years hospitalized for an acute MI in a coronary care unit of all public or privately funded hospitals receiving MI emergencies in the region of Côte d'Or (France) since 2001. Cases were ascertained by the prospective collection of consecutive admissions. MI was identified by an increase in serum troponin I (greater than the upper limit of normal for each hospital) and clinical symptoms of ischemia and/or characteristic electrocardiographic signs.

For the current study, patients hospitalized for an acute MI at the Dijon University Hospital and who underwent coronary angiography between 2012 and 2019 were included. A retrospective analysis of coronary angiographies was performed using a digital medium (Intellispace Cardiovascular ${ }^{\mathrm{TM}}$ ). Acute MI was defined according to the current universal definition [21].

The probability of $\mathrm{FH}$ was calculated from the sum of the points from an adapted version of the Dutch Lipid Clinic Network (DLCN) score criteria [4]: family history of premature $\mathrm{CAD}$ in a first-degree relative (male $<55$ years and female $<60$ years; 1 point); personal history of premature CAD (2 points) or vascular disease (1 point); and LDL-cholesterol (LDL-C) value: $330 \mathrm{mg} / \mathrm{dL}$ [8 points], 250-329 mg/dL [5 points], 190-249 mg/dL [3 points], $155-189 \mathrm{mg} / \mathrm{dL}$ [1 point]). In individuals on lipidlowering therapy, LDL-C at admission was corrected for the drug class: statins (130\%), ezetimibe (120\%), and statins and ezetimibe (140\%). A conservative correction factor for statin treatment (130\%) was chosen because moderate intensity statins are mostly used in France. The presence of tendon xanthomas or corneal arches and a family history of hypercholesterolemia or vascular disease were not recorded in the database. Missing information was counted as zero. For each patient, the diagnosis of $\mathrm{FH}$ was considered certain or probable when the total score was $\geq 6$, and absent when the score was $<3$.

Among the patients included in the RICO database, 120 were categorized as certain or probable $\mathrm{FH}$ (score $\geq$ 6) and 4243 as unlikely FH (non-FH; score $<3$ ). The characteristics of the main cohort have already been described [7]. The $120 \mathrm{FH}$ patients were matched (1:2) with 234 non-FH patients from the database based on age ( \pm standard deviation), sex, and presence of type 2 diabetes. The flow chart is described in Fig. 1. 


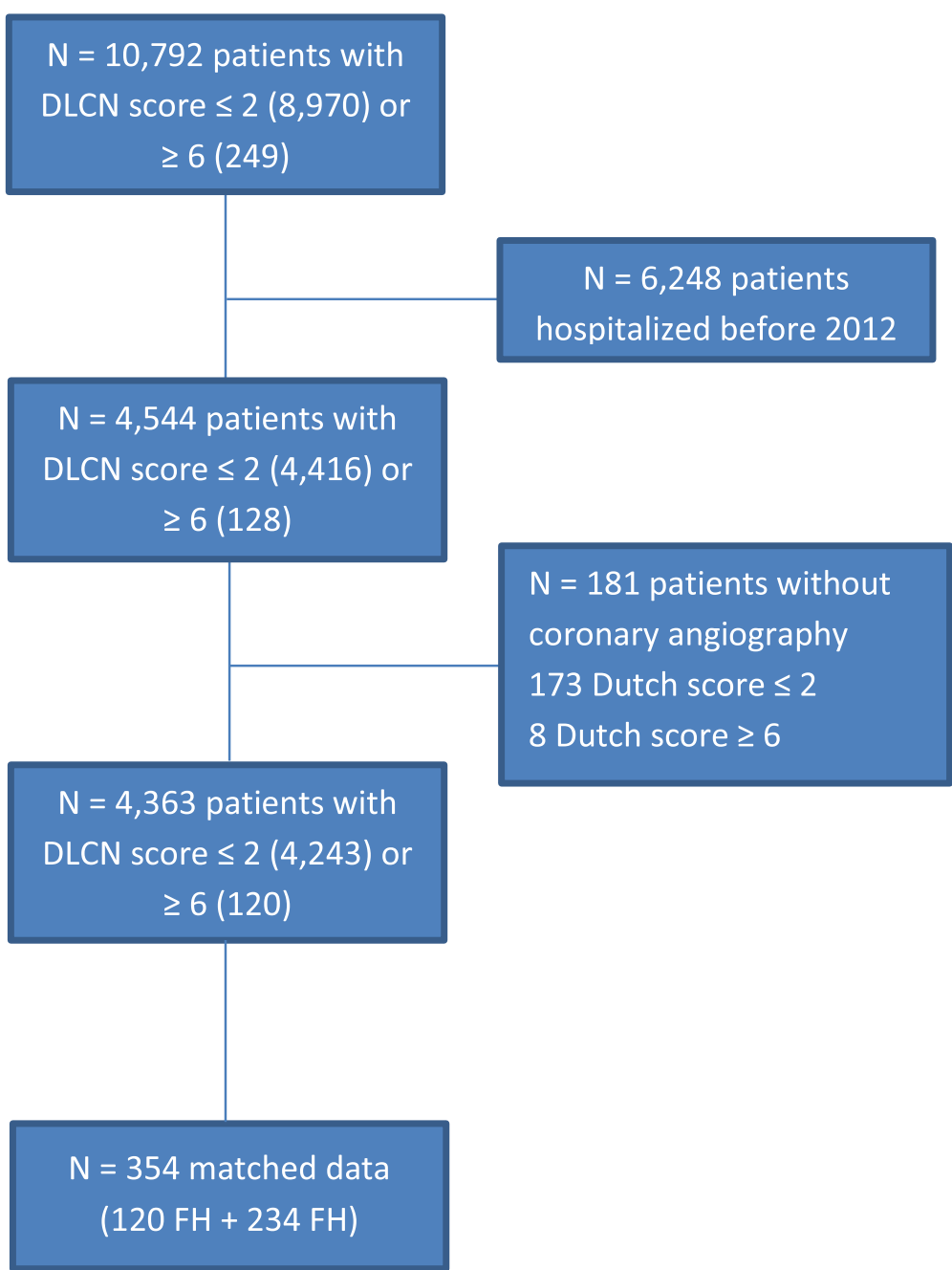

Fig. 1 Flow chart

We analyzed risk factors, CV history (defined as history of $\mathrm{MI}$, percutaneous coronary intervention (PCI) or coronary artery bypass graft surgery (CABG), lipid-lowering medications, time to admission, clinical data at admission, and hospital complications. Left ventricular ejection fraction (LVEF) was assessed within $12 \mathrm{~h}$ of admission using the Simpson biplane method. Blood lipids and other biological parameters were obtained on admission, except for peak troponin Ic, which was determined from 3 samples taken at 8$\mathrm{h}$ intervals in the first $24 \mathrm{~h}$ after admission. We also calculated the GRACE score for each patient [22] according to age, Killip class, systolic blood pressure, heart rate, ST segment changes, cardiac arrest on admission, creatinine levels and cardiac enzyme elevation.

\section{Evaluation of coronary angiography lesions and patient management}

Coronary angiography images were reviewed by two trained interventional cardiologists who were blinded to the patient's group. There was a discrepancy in 7 cases, which were then adjudicated through a joint review.

Coronary angiography was considered normal when the angiographic images did not show any visible atheromatous plaque or spastic phenomena. Coronary lesions were considered non-significant for stenoses $<50 \%$ (and significant when stenoses were $\geq 50 \%$ ). Depending on the number of diseased vessels $(\geq 2.5 \mathrm{~mm})$, multivessel CAD was considered when they were located on the left anterior descending artery and/or the diagonal branches, the left circumflex artery and marginal arteries, the right coronary artery (and/or the posterior interventricular or the left retro ventricular arteries), with or without involvement of the left main artery. 
For each patient, initial SYNTAX scores (before the revascularization procedure) and residual SYNTAX scores (after the revascularization procedure) were calculated [23].

Complex lesions were identified according to prespecified criteria from the CHAMPION-PHOENIX [24] and DAPT [18] studies: left main lesion, long lesion > $20 \mathrm{~mm}$, multiple lesions (> 2 lesions per vessel), bifurcation lesion (with side branch $>1.5 \mathrm{~mm}$ ), significant tortuosity (two between 45 and $90^{\circ}$ or one greater than $90^{\circ}$ in the vicinity of the lesion), thrombus, angulation, eccentricity, and stenting of a saphenous graft. Moderate calcifications (radio-opaque density during the cardiac cycle and affecting only on one edge of the vascular wall) or severe calcifications (radio-opaque density visualized even in the absence of cardiac movement before injection of the contrast agent and most often throughout the arterial wall) were identified. Multiple complex lesions were defined by the presence of several complex lesions [17].

Coronary angiographic data were collected: TIMI flow, culprit artery, number of diseased vessels, stents (number, diameter, length and type), and revascularization strategies (thrombectomy, PCI and CABG). In-hospital $\mathrm{CV}$ events were also analyzed (recurrent MI, stroke, heart failure, or death). Heart failure (HF) was defined by Killip class $>1$.

\section{Ethics approval and consent to participate}

Informed consent was obtained for each patient prior to inclusion in the study. The study protocol was authorized by the Ethics Committee of the Dijon University Hospital.

\section{Statistical analysis}

The categorical variables, expressed in numbers and percentages, were compared using Pearson's Chi-square tests or Fisher's exact tests. Continuous variables, presented as medians [interquartile range], were compared by the Student or Mann-Whitney/Wilcoxon test. The normality of the variables was determined using Kolmogorov-Smirnov test. Significance was set at $P<0.05$.

Multivariate logistic regression analyses were used to identify factors associated with multiple complex coronary lesions ( $>1$ complex anatomical feature) or multivessel CAD (>1 coronary vessel with significant stenosis). Multivariate models were built by including predictive variables in univariate analysis, with an inclusion threshold of $P<0.10$. Although not significant in univariate analyses, sex and diabetes were included as forced variables in the multivariate models, given their impact on the dependent variable. The threshold for defining high CRP levels $(\mathrm{CRP}>3 \mathrm{mg} / \mathrm{L})$ was chosen for its clinical relevance. Statistical analyses were performed using SPSS version 12.0.1 (IBM Inc.).

\section{Results}

FH patients (DLCN score $\geq 6)(n=120)$ were compared to non-FH patients $(\mathrm{DLCN}<3)(n=234)$ (Table 1$)$. FH patients had a higher incidence of hypertension $(P=$ 0.002 ) and, as expected, a higher incidence of personal or family history of CAD $(p<0.001)$. Statins $(P<0.001)$ and ezetimibe $(P<0.001)$ were prescribed more often to $\mathrm{FH}$ patients. However, although LDL-cholesterol was high (208 [174-239] mg/dL), less than half of FH patients had a prescription for chronic statin treatment. As expected, FH patients had higher levels of LDL-C and triglycerides $(P<0.001$ for both). On admission, the rate of ST-segment-elevation MI was similar for both groups $(P=0.355)$, as was the GRACE risk score $(P=0.20)$.

The median length of stay in the coronary care unit was 4 [3-5] days for both groups. FH and no-FH patients had similar rates of in-hospital events (HF: 20 (16.7\%) vs 41 (17.5\%), $P=0.840$; recurrent $\mathrm{MI}: 2(1.7 \%)$ vs $3(1.3 \%), P=1$; stroke: $1(0.8 \%)$ vs $1(0.4 \%), P=1$; death $1(0.8 \%)$ vs $2(0.9 \%), P=1)$.

Angiographic data are shown in Table 2. The percentage of optically healthy coronary arteries was much less frequent in $\mathrm{FH}$ patients than in non-FH patients, 3\% vs $10 \%(P=0.029)$, respectively, and $4 \mathrm{FH}$ patients had coronary arteries without stenosis. Compared to the non$\mathrm{FH}$ group, patients in the $\mathrm{FH}$ group had a higher initial SYNTAX score $(11[6-20]$ vs $8[3-15], P=0.005)$ and more frequent multivessel disease $(56 \%$ versus $40 \%, P=$ 0.01) (Fig. 2). In contrast, the residual SYNTAX score was comparable between the two groups $(P=0.47)$. In FH patients, significant lesions were more often located on left circumflex and marginal arteries $(p=0.028)$, right coronary $(P=0.041)$ and the left retro ventricular artery $(P=0.04)$. On the other hand, no difference was found for the location of the culprit artery $(P=0.213)$. The rate of PCI $(P=0.84)$ and the number of implanted stents $(P=0.96)$ were not significantly different between groups, but $\mathrm{CABG}$ was more common in $\mathrm{FH}$ patients $(P=0.037)$.

The number of coronary lesions and their complexity characteristics are reported in Table 3 and Fig. 3. There was no difference between the 2 groups on the overall distribution of the number of complex anatomical features $(P=0.129)$. However, there was a non-significant trend towards more multiple complex lesions $(>1)$ in FH patients $(P=0.053)$. Our findings indicate that $\mathrm{FH}$ patients had more multiple lesions $(P=0.022)$, bifurcation lesions $(P=0.017)$, and calcified lesions $(P=$ 0.033 ) (Fig. 3). Finally, there was a trend in toward longer lesions FH patients $(P=0.053)$, but with less thrombotic burden $(P=0.056)$. 
Table 1 Baseline characteristics. (n (\%) or median (IQR))

\begin{tabular}{|c|c|c|c|}
\hline & $\begin{array}{l}\text { Dutch Lipid Clinic } \\
\text { Network } \\
\text { score } 0-2 \\
N=234\end{array}$ & $\begin{array}{l}\text { Dutch Lipid Clinic } \\
\text { Network } \\
\text { score } \geq 6 \\
N=120\end{array}$ & $P$ \\
\hline \multicolumn{4}{|l|}{ CV risk factors } \\
\hline Age, years & $52(46-59)$ & $51(46-59)$ & 0.925 \\
\hline Female & 89 (38\%) & $43(36 \%)$ & 0.685 \\
\hline $\mathrm{BMl}, \mathrm{kg} / \mathrm{m}^{2}$ & $27(23-30)$ & $27(24-31)$ & 0.098 \\
\hline Hypercholesterolemia & $61(26 \%)$ & $86(72 \%)$ & $<0.001$ \\
\hline Hypertension & 87 (37\%) & $65(54 \%)$ & 0.002 \\
\hline Diabetes & 45 (19\%) & $17(14 \%)$ & 0.235 \\
\hline Smoking & 137 (59\%) & $68(57 \%)$ & 0.734 \\
\hline Prior CAD & $17(7 \%)$ & $25(21 \%)$ & $<0.001$ \\
\hline Family history of CAD & $13(6 \%)$ & 87 (73\%) & $<0.001$ \\
\hline Stroke & $14(6 \%)$ & $7(6 \%)$ & 0.955 \\
\hline PAD & $6(3 \%)$ & $6(5 \%)$ & 0.232 \\
\hline \multicolumn{4}{|l|}{ Medications on admission } \\
\hline Ezetrol & $3(1 \%)$ & $14(12 \%)$ & $<0.001$ \\
\hline Fibrate & $8(3 \%)$ & $1(1 \%)$ & 0.283 \\
\hline Statins & $31(13 \%)$ & $56(47 \%)$ & $<0.001$ \\
\hline \multicolumn{4}{|l|}{ Discharge medications } \\
\hline Ezetrol & $4(2 \%)$ & $12(10 \%)$ & $<0.001$ \\
\hline Fibrate & $2(1 \%)$ & $0(0 \%)$ & 0.551 \\
\hline Statins & 212 (91\%) & 111 (93\%) & 0.549 \\
\hline \multicolumn{4}{|l|}{ Clinical data } \\
\hline $\mathrm{HR}$, beats/min & 77 [66-90]; $n=228$ & 80 [70-94]; $n=118$ & 0.197 \\
\hline $\mathrm{SBP}, \mathrm{mmHg}$ & $139 \pm 29 ; n=228$ & $145 \pm 26 ; n=118$ & 0.048 \\
\hline $\mathrm{DBP}, \mathrm{mmHg}$ & $85 \pm 20 ; n=228$ & $90 \pm 19 ; n=117$ & 0.033 \\
\hline Time to admission, $\min$ & $171[97-388] ; n=227$ & 175 [93-429]; $n=113$ & 0.964 \\
\hline LVEF, \% & $55[45-60] ; n=233$ & 55 [45-60] & 0.617 \\
\hline LVEF $<40 \%$ & $26(11 \%)$ & $7(6 \%)$ & 0.104 \\
\hline GRACE Score & 116 [96-138]; $n=224$ & $110[93-131] ; n=115$ & 0.200 \\
\hline $\mathrm{HF}$ & $37(16 \%)$ & $17(14 \%)$ & 0.684 \\
\hline STEMI & 133 (57\%) & $62(52 \%)$ & 0.355 \\
\hline Anterior wall location & $86(37 \%)$ & $35(29 \%)$ & 0.154 \\
\hline \multicolumn{4}{|l|}{ Biological data } \\
\hline Total cholesterol, mg/dL & 194 [169-214] & 285 [250-320] & $<0.001$ \\
\hline HDL cholesterol. mg/dL & 47 [3658] & $45[36-54]$ & 0.194 \\
\hline LDL cholesterol. mg/dL & 119 [95-138] & 208 [174-239] & $<0.001$ \\
\hline LDL cholesterol, corrected $\geq 190 \mathrm{mg} / \mathrm{dL}$ & $0(0 \%)$ & $117(98 \%)$ & $<0.001$ \\
\hline Triglycerides. mg/dL & $125[85-176]$ & 149 [103-221] & 0.001 \\
\hline $\mathrm{CRP} \geq 3 \mathrm{mg} / \mathrm{L}$ & $130(56 \%)$ & $82(68 \%)$ & 0.020 \\
\hline
\end{tabular}

Data are expressed as $\mathrm{n}(\%)$ or medians (IQR)

CRP C-reactive protein, $P A D$ peripheral artery disease, BMI Body Mass index, CAD coronary artery disease, HF Herat failure, HR Heart rate, SBP systolic blood pressure, DBP Diastolic blood pressure, LVEF Left ventricular ejection fraction, STEMI ST segment elevation MI 
Table 2 Coronary angiography data and revascularization procedures

\begin{tabular}{|c|c|c|c|}
\hline & $\begin{array}{l}\text { Dutch Lipid Clinic } \\
\text { Network } \\
\text { score } 0-2 \\
N=234\end{array}$ & $\begin{array}{l}\text { Dutch Lipid Clinic } \\
\text { Network } \\
\text { score } \geq 6 \\
N=120\end{array}$ & $P$ \\
\hline SYNTAX Score (initial) & $8[3-15] ; n=225$ & $11[6-20] ; n=119$ & 0.005 \\
\hline SYNTAX score (residual) & $2(0-7) ; n=171$ & $2(0-8) ; n=85$ & 0.472 \\
\hline Optically normal arteries & $23(10 \%)$ & $4(3 \%)$ & 0.029 \\
\hline \multicolumn{4}{|l|}{ Significant stenosis } \\
\hline Left main & $6(3 \%)$ & $5(4 \%)$ & 0.519 \\
\hline LAD & $120(51 \%)$ & $73(61 \%)$ & 0.088 \\
\hline Diagonal branch & $41(18 \%)$ & $30(25 \%)$ & 0.096 \\
\hline LAD or diagonal branch & $132(56 \%)$ & $79(66 \%)$ & 0.087 \\
\hline$C x$ & $64(27 \%)$ & 39 (33\%) & 0.313 \\
\hline Marginal artery & $29(12 \%)$ & $30(25 \%)$ & 0.003 \\
\hline Cx or marginal artery & $81(35 \%)$ & $56(47 \%)$ & 0.028 \\
\hline RCA & $98(42 \%)$ & $64(53 \%)$ & 0.041 \\
\hline PIA & $9(4 \%)$ & $6(5 \%)$ & 0.610 \\
\hline LRA & $9(4 \%)$ & $11(9 \%)$ & 0.040 \\
\hline RCA or PIA or LRA & 107 (46\%) & 70 (58\%) & 0.025 \\
\hline Multi-vessel disease & 93 (40\%) & 67 (56\%) & 0.004 \\
\hline Culprit artery & $N=188$ & $N=106$ & 0.213 \\
\hline Left main & $2(1 \%)$ & $4(4 \%)$ & \\
\hline LAD & $83(44 \%)$ & $48(45 \%)$ & \\
\hline$C x$ & $29(16 \%)$ & $21(20 \%)$ & \\
\hline RCA & 74 (39\%) & $33\left(31 \%{ }^{\circ}\right.$ & \\
\hline TIMI flow $<2$ on culprit artery & $92 / 188(49 \%)$ & $56 / 106(53 \%)$ & 0.521 \\
\hline \multicolumn{4}{|l|}{ Revascularisation } \\
\hline $\mathrm{PCl}$ & $172(74 \%)$ & 87 (73\%) & 0.840 \\
\hline Thrombectomy & 62/173 (36\%) & 30/91 (33\%) & 0.642 \\
\hline CABG & $11 / 223(5 \%)$ & 13/118 (11\%) & 0.037 \\
\hline Stent number & $N=174$ & $N=88$ & 0.969 \\
\hline 0 & $15(9 \%)$ & $6(7 \%)$ & \\
\hline 1 & $129(74 \%)$ & 66 (75\%) & \\
\hline 2 & $25(14 \%)$ & $13(15 \%)$ & \\
\hline 3 & $5(3 \%)$ & $3(3 \%)$ & \\
\hline Stent type & $N=159$ & $N=82$ & 0.312 \\
\hline BMS & $36(23 \%)$ & $14(17 \%)$ & \\
\hline DES & $123(77 \%)$ & $68(83 \%)$ & \\
\hline Stent diameter $>3 \mathrm{~mm}$ & $100 / 159(63 \%)$ & $46 / 82(56 \%)$ & 0.279 \\
\hline
\end{tabular}

Data are expressed as $\mathrm{n}(\%)$ or medians (IQR)

$L A D$ left anterior descending, $R C A$ right coronary artery, $C x$ left circumflex, $C A B G$ coronary artery bypass graft, $B M S$ bare metal stent, $D E S$ drug-eluting stent, $P C I$ percutaneous coronary intervention, TIMI Thrombolysis in acute myocardial infarction, PIA posterior interventricular artery, $L R A$ left retroventricular artery

In multivariate analysis, only age (OR 1.033; $95 \% \mathrm{CI}$ 1.011-1.055) and LDL-cholesterol level (OR 2.141; 95\% CI 1.161-3.949) were associated with lesion complexity ( $>1$ complex anatomical feature) after adjustment for gender, diabetes, chronic statin therapy, FH diagnosis, and a $\mathrm{CRP} \geq 3 \mathrm{mg} / \mathrm{L}$ (Table 4). The presence of $\mathrm{FH}$, which tended to be associated with multiple complex lesions in univariate analysis, did not persist after adjustment for LDL-C. Furthermore, given the close link between inflammation and hypercholesterolemia, we 


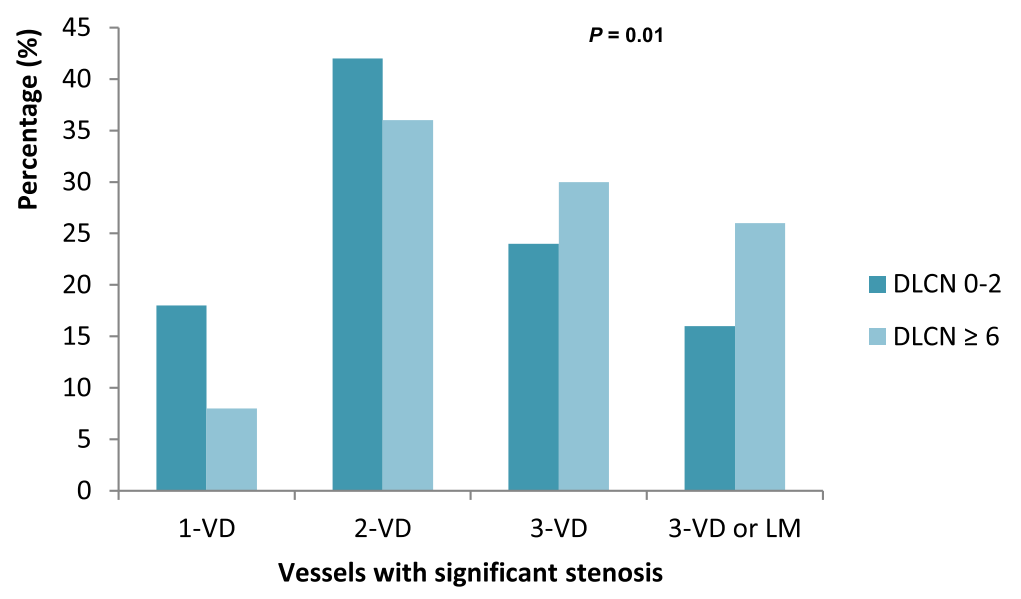

Fig. 2 Rate of vessels with significant stenosis

tested the interaction between CRP and LDL-cholesterol in the multivariate model $(P$ interaction $=0.005)$. The introduction of this interaction did not alter the conclusions of the model. Table 5 shows the variables associated with multivessel disease. Neither FH nor LDL-C levels persist as predictors when adjusted for confounding factors. However, high CRP levels were strongly associated with the development of multivessel disease, as was age ( $P=0.004$ and $P=0.002$, respectively).

\section{Discussion}

Only few studies have assessed the characteristics of coronary lesions in FH patients hospitalized for acute MI [7, $8,12-15]$. After matching for the main factors associated with CAD, the findings of this study suggest that the FHassociated high cholesterol burden, which starts at an early age, and inflammation are associated with CAD severity. Here, severe CAD is characterized by multivessel disease, a high SYNTAX score, and anatomical complexity features, including bifurcation lesions and calcified plaques (Fig. 4). These data are consistent with previous studies that included patients with genetically-determined $\mathrm{FH}$ $[14,16,25]$.

Wang et al. [8] reported frequent multi-vessel lesions in $\mathrm{FH}$ patients, while non-FH patients had more frequent one-vessel CAD (multi-vessel CAD: 75.7\% versus 34.1\% and one-vessel CAD; $54.3 \%$ versus $21.6 \%$, respectively, $P<$ 0.001). This finding was also reported in 2 other studies, although in patients with possible $\mathrm{FH}[13,14]$. In a recent study of 382 young survivors ( $\leq 40$ years old) of acute MI, patients with HF were three times more likely to have multiple vessel lesion location $(36.2 \%$ versus $12.8 \%, P=$ 0.011) [26]. Similar to the current study, a small number of patients with angiographically healthy coronary arteries or with non-significant lesions were found, $(n=4)$, but these individuals were considerably less likely to be $\mathrm{FH}$ patients [12]. Two recent Chinese studies investigated CAD extension in $\mathrm{FH}$ patients $[8,15]$ using Gensini

Table 3 Anatomical complexity of the coronary lesions

\begin{tabular}{lll}
\hline & $\begin{array}{l}\text { Dutch Lipid Clinic } \\
\text { Network } \\
\text { score } \mathbf{0 - 2} \\
\mathbf{N = 2 3 4}\end{array}$ & $\begin{array}{l}\text { Dutch Lipid Clinic } \\
\text { Network } \\
\text { score } \geq \mathbf{6} \\
\boldsymbol{N}=\mathbf{1 2 0}\end{array}$ \\
\hline $\begin{array}{ll}\boldsymbol{P} \\
\text { Number of complex characteristics }\end{array}$ & $56(24 \%)$ & $23(19 \%)$ \\
0 & $65(28 \%)$ & $26(22 \%)$ \\
1 & $73(31 \%)$ & $37(31 \%)$ \\
2 & $25(11 \%)$ & $18(15 \%)$ \\
3 & $10(4 \%)$ & $11(9 \%)$ \\
4 & $4(2 \%)$ & $3(2 \%)$ \\
5 & $0(0 \%)$ & $2(2 \%)$ \\
7 & $1(0.4 \%)$ & $0(0 \%)$ \\
Multiple complex lesions (number $>$ 1) & $113(48 \%)$ & $71(59 \%)$ \\
\hline
\end{tabular}




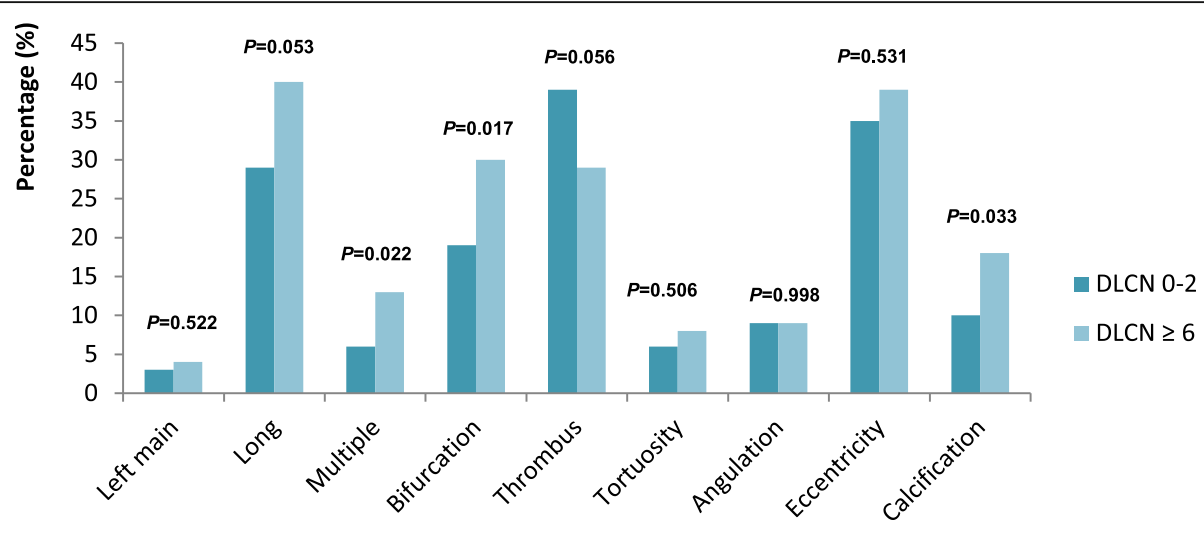

Complex anatomical charcteristics of coronary lesions

Fig. 3 Complex anatomical characteristics of coronary lesions

angiographic criteria [27], which is limited to severity of stenosis (estimated as a percentage), coronary plaque features and lesion location (proximal or distal). FH patients had more severe coronary injury $[8,15]$, and male sex was significantly associated with complex lesions, in agreement with previous studies $[18,24]$. This work on a young FH population (mean age 51 years) further suggests that in addition to the LDL-C burden, inflammation plays a role in promoting the extension of $\mathrm{CAD}$, as highlighted by higher CRP levels [28, 29].

To the best of our knowledge, this is the first study to use validated complexity criteria to evaluate the coronary lesions of FH subjects on coronary angiography [18, 24]. We found that the number of multiple complex lesions was mainly related to age and LDL-C levels. Moreover, bifurcated lesions, large calcifications, and the presence of multiple lesions were the key anatomical features characterizing complex $\mathrm{CAD}$ in $\mathrm{FH}$ patients. In asymptomatic FH patients, Pang et al. [16] also found more calcified plaques, especially on the left main artery, and a higher calcium score using coronary computed tomography (CT).
PCI are high-risk procedures when done in calcified and bifurcated lesions, and recent studies, including a metaanalysis, have shown that these complex features have a major impact on the recurrence of ischemic events and long-term mortality [30, 31]. Moreover, in randomized clinical trials, the lesion complexity score was an independent predictor of short- and medium-term ischemic risk. The CHAMPION-PHOENIX trial, which included 10,854 patients with chronic or acute coronary syndrome, showed that a combined endpoint of all-cause death, recurrent MI, new revascularization guided by an ischemia test, or stent thrombosis within $48 \mathrm{~h}$ after PCI, was significantly related to the identified number of lesion complexity features (OR 1.68, 95\% CI 1.20-2.36; OR 2.78, 95\% CI 2.00-3.87; and OR 3.23, 95\% CI 2.33-4.48, $P<0.0001$, for 1,2 , and 3 complex features compared with no complex features, respectively) [24]. This association was observed up to 30 days of follow-up. In the DAPT study, patients with complex coronary anatomy (defined by the presence of at least 1 complexity criterion) had increased rates of major $\mathrm{CV}$ events $(5.3 \%$ versus $3.5 \% ; P<0.001)$ and $\mathrm{MI}$ or

Table 4 Logistic regression analysis to estimate lesion anatomical complexity (> 1 complex lesion)

\begin{tabular}{|c|c|c|c|c|}
\hline & Univariate & & Multivariate & \\
\hline Variable & OR $(95 \% \mathrm{Cl})$ & $P$ & OR $(95 \% \mathrm{Cl})$ & $P$ \\
\hline Female (vs male) & $0.800(0.520-1.232)$ & 0.311 & $0.570(0.346-0.940)$ & 0.028 \\
\hline Age, per y & $1.027(1.009-1.045)$ & 0.003 & $1.035(1.014-1.057)$ & 0.001 \\
\hline Diabetes (vs no diabetes) & $1.150(0.663-1.993)$ & 0.620 & $0.889(0.481-1.642)$ & 0.707 \\
\hline Prior CAD (vs no CAD) & $1.584(0.818-3.068)$ & 0.173 & - & \\
\hline Chronic statins (vs no statins) & $0.822(0.506-1.334)$ & 0.427 & - & \\
\hline $\mathrm{FH}$ (DLCN score $\geq 6$ vs $\leq 2$ ) & $1.246(0.997-1.556)$ & 0.053 & $0.890(0.628-1.259)$ & 0.510 \\
\hline LDL cholesterol. Per g/L & $1.759(1.215-2.546)$ & 0.003 & $1.948(1.090-3.480)$ & 0.024 \\
\hline $\mathrm{CRP} \geq 3 \mathrm{mg} / \mathrm{L}(\mathrm{vs} C R P<3 \mathrm{mg} / \mathrm{L})$ & $1.590(1.036-2.438)$ & 0.034 & $1.366(0.873-2.136)$ & 0.172 \\
\hline
\end{tabular}

OR Odds ratio, CI confidence interval, FH familial hypercholesterolemia, DLCN Dutch Lipid Clinic Network, LDL Low density lipoprotein, CAD coronary artery disease, CRP C-Reactive Protein 
Table $\mathbf{5}$ Logistic regression analysis to estimate multivessel disease

\begin{tabular}{|c|c|c|c|c|}
\hline & Univariate & & Multivariate & \\
\hline Variable & OR $(95 \% \mathrm{CI})$ & $P$ & OR $(95 \% \mathrm{Cl})$ & $P$ \\
\hline Female (vs male) & $0.878(0.569-1.355)$ & 0.557 & $0.661(0.398-1.099)$ & 0.110 \\
\hline Age pery & $1.030(1.012-1.048)$ & 0.001 & $1.031(1.010-1.052)$ & 0.004 \\
\hline Diabetes (vs no diabetes) & $1.732(0.996-3.011)$ & 0.052 & $1.362(0.737-2.516)$ & 0.324 \\
\hline Prior CAD & $1.546(0.809-2.954)$ & 0.187 & - & \\
\hline Chronic statins & $1.179(0.726-1.914)$ & 0.507 & - & \\
\hline FH (DLCN score $\geq 6$ vs $\leq 2$ ) & $1.384(1.108-1.730)$ & 0.004 & $1.248(0.881-1.766)$ & 0.212 \\
\hline LDL cholesterol. Per mg/dL & $1.592(1.113-2.278)$ & 0.011 & $1.177(0.672-2.059)$ & 0.569 \\
\hline CRP $\geq 3 \mathrm{mg} / \mathrm{L}(\mathrm{vs} C R P<3 \mathrm{mg} / \mathrm{L})$ & $2.428(1.559-3.782)$ & $<0.001$ & $2.099(1.326-3.323)$ & 0.002 \\
\hline
\end{tabular}

OR Odds ratio, $\mathrm{Cl}$ confidence interval, FH familial hypercholesterolemia, DLCN Dutch Lipid Clinic Network, LDL Low density lipoprotein, CAD coronary artery disease, CRP C-Reactive Protein

stent thrombosis $(3.9 \%$ versus $2.4 \% ; P<0.001)$ within 1 year, but these differences did not persist beyond 12 months [18]. Further work is needed to determine whether these characteristics could impact the short-term prognosis of $\mathrm{FH}$ patients after MI.

A recent French study on the 2005 and 2010 cohorts of the FAST-MI registry showed that an LDL-C target may be difficult to achieve in FH patients with acute MI. Even though they received intensive lipid-lowering therapy at discharge (statin + ezetimibe), FH patients had much higher LDL-C levels than non-FH patients at 5 years of follow-up $(123 \mathrm{mg} / \mathrm{dL}$ and $83 \mathrm{mg} / \mathrm{dL}$ respectively, $P<0.001$ ) [32]. In addition, and during intensive lipid-lowering treatment, FH patients had an increased risk of death, MI recurrence and stroke, even after adjustment for $\mathrm{CV}$ risk factors, suggesting the need for more aggressive management. On the other hand, and beyond LDL-C concentration, some factors such as female sex, high HDL-C levels, not smoking and elevated adiponectin may contribute to improved cardiovascular event-free survival in $\mathrm{FH}$ patients [33].
As secondary prevention, PCSK9 inhibitors such as alirocumab or evolocumab can be used to lower LDL-C and have demonstrated their clinical benefit in addition to intensive statin treatment [34]. Moreover, PCSK9 inhibitors provide better adherence than statins and can help to improve compliance to statin treatment in a real-world setting [35].. Among 4015 post-MI patients, it was demonstrated that full adherence to treatment is associated with a lower rate of adverse cardiovascular events after 2-years follow-up, and reduction of annual direct medical costs for MI hospitalization [36].

\section{Study strengths and limitations}

The presence of DLCN criteria, such as tendon xanthomas or corneal arches, and a family history of high cholesterol or vascular disease were not collected in our database. This information bias may result in an underestimation of the true prevalence of $\mathrm{FH}$. However, the FH probability rate found in our population (approximately $3 \%)$ is consistent with other major studies $[9,14$, $25,32]$. In addition, it is likely that many of the $\mathrm{FH}$

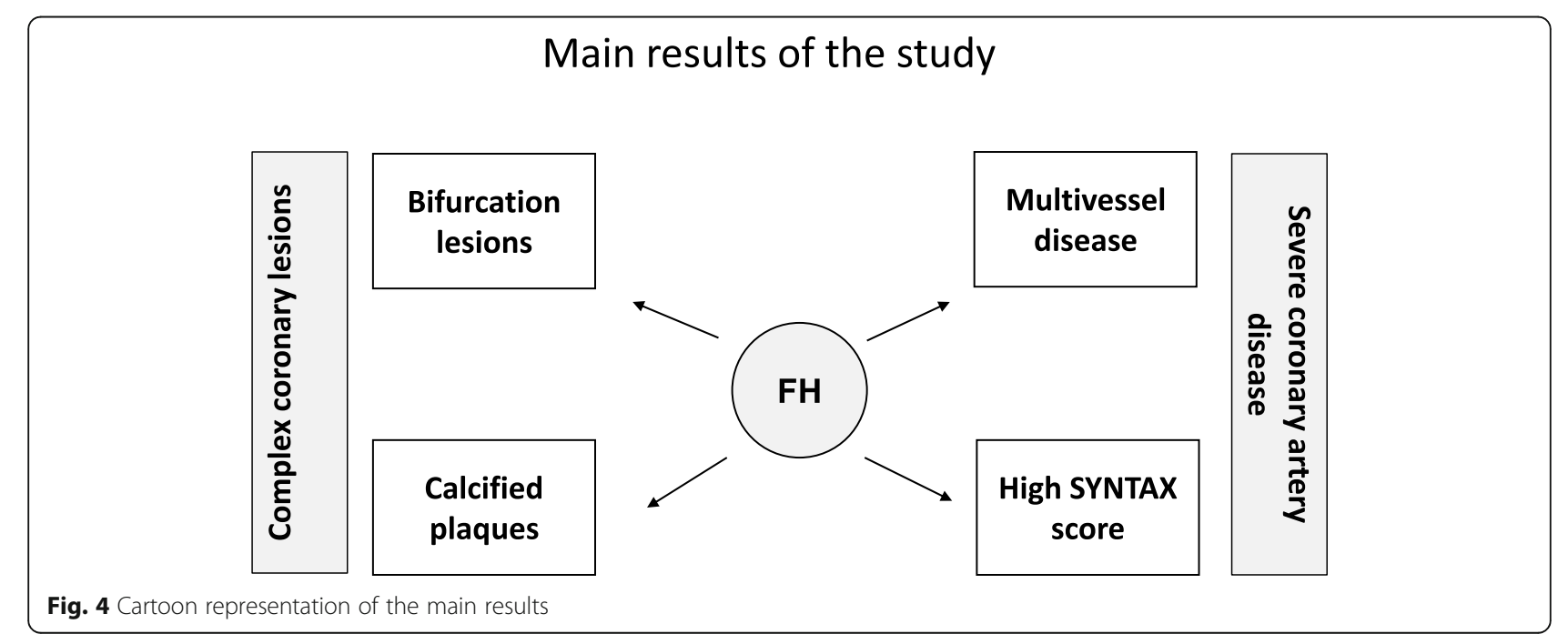


patients in our study had tendon xanthoma. In 394 Japanese coronary patients undergoing $\mathrm{PCI}$, most $\mathrm{FH}$ patients had Achilles heel xanthoma, which was predictive of the severity of coronary lesions [37]. Another recent series of 241 patients found that CAD patients had a high prevalence of Achilles heel xanthoma (18.2\%), which was associated with multi-vessel coronary disease and imaging vulnerability criteria for atheromatous plaques [38]. Other missing data in our study include the statins doses, but we applied a correction factor of $\approx 30 \%$ to LDL-C levels in order not to overestimate the probability of FH. Moreover, genetic testing was not performed to confirm FH in the present study. In another recent study, a genetic diagnosis was obtained in 57 of 84 patients with DLCN $\geq 6$ (67.9\%) [39]. However, the procedure used to calculate the probability of $\mathrm{FH}$ with the adapted Dutch lipid Clinic criteria is widely used in routine clinical practice.

Finally, the retrospective design of the study may potentially bias the results.

\section{Conclusion}

In patients with $\mathrm{HF}$ and acute MI, coronary lesions are anatomically complex, and characterized by multiple lesions, calcifications and bifurcation lesions. These features were associated with a high cholesterol burden and inflammation. The findings of this study reinforce the need for early screening for $\mathrm{FH}$ and highlight the fact that this condition is still under-treated. Aggressive cholesterollowering management is an important part of secondary prevention in these young high-risk patients.

\section{Abbreviations}

FH: Heterozygous familial hypercholesterolemia; LDL-C: LDL-cholesterol; PCSK9: Proprotein convertase subtilisin/kexin type 9; DLCN: Dutch Lipid Clinic Network; CV: Cardiovascular; CAD: Coronary artery disease; MI: Myocardial infarction; RICO: Côte d'Or Myocardial Infarction Observatory; PCl: Percutaneous coronary intervention; CABG: Coronary artery bypass graft surgery; LVEF: Left ventricular ejection fraction; HF: Heart failure;

$\mathrm{CT}$ : Computed tomography; ARS: Agence Régionale de Santé

\section{Acknowledgements}

We wish to thank Mrs. Suzanne Rankin for reviewing the English and Sylvie Mazencieux Agobert for editing assistance.

\section{Authors' contributions}

Conceptualization: MF, YC and MZ; data curation: HY, FB and MM; formal analysis: $M M$ and $M Z$; funding and acquisition: $M Z$ and $Y C$; investigation: $F C$, $\mathrm{FB}, \mathrm{PB}$ and $\mathrm{DB}$; methodology: $Y C$ and $M Z_{\text {; }}$ project administration, resources and supervision: $L R ; Y C$ and $M Z$; resources: $P B$ and $D B$; visualization: $M F$ and $M Z$; writing original draft: $\mathrm{HY}$ and $\mathrm{MZ}$; writing, review, and editing: all authors. All authors have read and agreed to the published version of the manuscript.

\section{Funding}

This work was supported by the Dijon-Bourgogne University Hospital, the Association de Cardiologie de Bourgogne, and by grants from the Agence Régionale de Santé (ARS) de Bourgogne Franche-Comté, and from the Regional Council of Bourgogne Franche-Comté.

\section{Availability of data and materials}

The data that support the findings of this study are available from DijonBourgogne University Hospital. However, restrictions apply to the availability of these data, which were used under license for the current study and are thus not publicly available. Data can be made available from the authors upon reasonable request and with permission from the Dijon-Bourgogne University Hospital.

\section{Declarations}

\section{Ethics approval and consent to participate}

All authors have read and approved submission of the manuscript and the manuscript has not been published and is not being considered for publication elsewhere in whole or part in any language.

\section{Consent for publication}

Not applicable.

\section{Competing interests}

MF reports having received grants, consulting fees and/or honoraria and delivering lectures for Abbott, Akcea/lonis, Amgen, AstraZeneca, DaïchiSankyo, Eli Lilly, Genzyme, Kowa, Merck and Co, Mylan, Pfizer, Sanofi/ Regeneron and Servier.

$Y C$ reports having received grants, consulting fees, honoraria and/or delivering lectures for Servier, Novartis, Boehringer, Pfizer, MSD, and Bayer. $\mathrm{MZ}$ received research grants from Amarin Corp.

No conflict of interest to disclose for the other authors.

\section{Author details}

${ }^{1}$ Cardiology Department, University Hospital Center Dijon Bourgogne, Dijon, France. ${ }^{2}$ PEC2, EA 7460, UFR Health Sciences, University of Bourgogne Franche Comté, Dijon, France. ${ }^{3}$ Private Hospital Dijon Bourgogne, Dijon, France.

Received: 4 March 2021 Accepted: 15 April 2021

Published online: 04 May 2021

\section{References}

1. Nordestgaard BG, Chapman MJ, Humphries SE, Ginsberg HN, Masana L, Descamps OS, et al. Familial hypercholesterolaemia is underdiagnosed and undertreated in the general population: guidance for clinicians to prevent coronary heart disease: consensus statement of the European atherosclerosis society. Eur Heart J. 2013;34(45):3478-90. https://doi.org/10.1 093/eurheartj/eht273.

2. Khera AV, Won H-H, Peloso GM, Lawson KS, Bartz TM, Deng X, et al. Diagnostic yield and clinical utility of sequencing familial hypercholesterolemia genes in patients with severe hypercholesterolemia. J Am Coll Cardiol. 2016;67(22): 2578-89. https://doi.org/10.1016/j.jacc.2016.03.520.

3. Wald DS, Bestwick JP, Morris JK, Whyte K, Jenkins L, Wald NJ. Child-parent familial hypercholesterolemia screening in primary care. N Engl J Med. 2016; 375(17):1628-37. https://doi.org/10.1056/NEJMoa1602777.

4. Mach F, Baigent C, Catapano AL, Koskinas KC, Casula M, Badimon L, et al. 2019 ESC/EAS guidelines for the management of dyslipidaemias: lipid modification to reduce cardiovascular risk. Eur Heart J. 2020:41(1):111-88. https://doi.org/10.1093/eurheartj/ehz455.

5. Benn M, Watts GF, Tybjaerg-Hansen A, Nordestgaard BG. Familial hypercholesterolemia in the danish general population: prevalence, coronary artery disease, and cholesterol-lowering medication. J Clin Endocrinol Metab. 2012;97(11):3956-64. https://doi.org/10.1210/jc.2012-1563.

6. Neil H a W, Hawkins MM, Durrington PN, Betteridge DJ, Capps NE, Humphries SE, et al. Non-coronary heart disease mortality and risk of fatal cancer in patients with treated heterozygous familial hypercholesterolaemia: a prospective registry study. Atherosclerosis. 2005;179:293-7.

7. Farnier M, Salignon-Vernay C, Yao H, Chague F, Brunel P, Maza M, et al. Prevalence, risk factor burden, and severity of coronary artery disease in patients with heterozygous familial hypercholesterolemia hospitalized for an acute myocardial infarction: data from the French RICO survey. J Clin Lipidol. 2019;13(4):601-7. https://doi.org/10.1016/j.jacl.2019.06.005.

8. Wang X, Cai G, Wang Y, Liu R, Xi Z, Li G, et al. Comparison of long-term outcomes of young patients after a coronary event associated with familial 
hypercholesterolemia. Lipids Health Dis. 2019;18(1):131. https://doi.org/10.11 86/s12944-019-1074-8.

9. Nanchen D, Gencer B, Muller O, Auer R, Aghlmandi S, Heg D, et al. Prognosis of patients with familial hypercholesterolemia after acute coronary syndromes. Circulation. 2016;134(10):698-709. https://doi.org/10.11 61/CIRCULATIONAHA.116.023007.

10. Tscharre M, Herman R, Rohla M, Piackova E, Vargas KG, Farhan S, et al. Prognostic impact of familial hypercholesterolemia on long-term outcomes in patients undergoing percutaneous coronary intervention. J Clin Lipidol. 2019;13(1):115-22. https://doi.org/10.1016/j.jacl.2018.09.012.

11. Mszar R, Grandhi GR, Valero-Elizondo J, Virani SS, Blankstein R, Blaha M, et al. Absence of coronary artery calcification in middle-aged familial hypercholesterolemia patients without atherosclerotic cardiovascular disease. JACC Cardiovasc Imaging. 2020;13(4):1090-2. https://doi.org/10.101 6/j.jcmg.2019.11.001.

12. Yasuda T, Shimizu M, Ino H, Okeie K, Yamaguchi M, Fujino N, et al. Coronary lesion morphology and prognosis in young males with myocardial infarction with or without familial hypercholesterolemia. Jpn Circ J. 2001; 65(4):247-50. https://doi.org/10.1253/jci.65.247.

13. Rerup SA, Bang LE, Mogensen UM, Engstrøm T, Jørgensen E, Pedersen F, et al. The prevalence and prognostic importance of possible familial hypercholesterolemia in patients with myocardial infarction. Am Heart J. 2016;181:35-42. https://doi.org/10.1016/j.ahj.2016.08.001.

14. Auckle R, Su B, Li H, Xu S, Xie M, Song Y, et al. Familial hypercholesterolemia in Chinese patients with premature ST-segment-elevation myocardial infarction: prevalence, lipid management and 1-year follow-up. PLoS One. 2017;12(10):e0186815. https://doi.org/10.1371/journal.pone.0186815.

15. Li J-J, Li S, Zhu C-G, Wu N-Q, Zhang Y, Guo Y-L, et al. Familial hypercholesterolemia phenotype in Chinese patients undergoing coronary angiography. Arterioscler Thromb Vasc Biol. 2017;37(3):570-9. https://doi. org/10.1161/ATVBAHA.116.308456.

16. Pang J, Abraham A, Vargas-García C, Bates TR, Chan DC, Hooper AJ, et al. An age-matched computed tomography angiographic study of coronary atherosclerotic plaques in patients with familial hypercholesterolaemia. Atherosclerosis. 2020;298:52-7. https://doi.org/10.1016/j.atherosclerosis.2020. 03.001 .

17. Rioufol G, Zeller M, Dentan G, Laurent Y, L'Huillier I, Ravisy J, et al. Predictors and prognosis for complex coronary lesions in patients with acute myocardial infarction: data from RICO survey. Am Heart J. 2007;154(2):330-5. https://doi.org/10.1016/j.ahj.2007.04.013.

18. Yeh RW, Kereiakes DJ, Steg PG, Cutlip DE, Croce KJ, Massaro JM, et al. Lesion complexity and outcomes of extended dual antiplatelet therapy after percutaneous coronary intervention. J Am Coll Cardiol. 2017;70(18):2213-23. https://doi.org/10.1016/j.jacc.2017.09.011.

19. Giustino G, Chieffo A, Palmerini T, Valgimigli M, Feres F, Abizaid A, et al. Efficacy and safety of dual antiplatelet therapy after complex PCI. J Am Coll Cardiol. 2016;68(17):1851-64. https://doi.org/10.1016/j.jacc.2016.07.760.

20. Beer JC, Dentan G, Janin-Magnificat L, Zeller M, Laurent $Y$, Ravisy J, et al. Beneficial effects of direct call to emergency medical services on time delays and management of patients with acute myocardial infarction. The RICO (obseRvatoire des Infarctus de Côte-d'Or) data. Ann Cardiol Angeiol. 2002;51(1):8-14. https://doi.org/10.1016/50003-3928(01)00057-9.

21. Thygesen K, Alpert JS, Jaffe AS, Chaitman BR, Bax JJ, Morrow DA, et al. Fourth universal definition of myocardial infarction (2018). Eur Heart J. 2019; 40(3):237-69. https://doi.org/10.1093/eurheartj/ehy462.

22. Granger CB, Goldberg RJ, Dabbous O, Pieper KS, Eagle KA, Cannon CP, et al. Predictors of hospital mortality in the global registry of acute coronary events. Arch Intern Med. 2003;163(19):2345-53. https://doi.org/10.1001/a rchinte.163.19.2345.

23. Sianos G, Morel M-A, Kappetein AP, Morice M-C, Colombo A, Dawkins K, et al. The SYNTAX score: an angiographic tool grading the complexity of coronary artery disease. Eurolntervention. 2005;1(2):219-27.

24. Stone GW, Généreux P, Harrington RA, White HD, Gibson CM, Steg PG, et al. Impact of lesion complexity on peri-procedural adverse events and the benefit of potent intravenous platelet adenosine diphosphate receptor inhibition after percutaneous coronary intervention: core laboratory analysis from 10854 patients from the CHAMPION PHOENIX trial. Eur Heart J. 2018; 39(46):4112-21. https://doi.org/10.1093/eurheartj/ehy562.

25. Al-Rasadi K, Al-Zakwani I, Alsheikh-Ali AA, Almahmeed W, Rashed W, Ridha $\mathrm{M}$, et al. Prevalence, management, and outcomes of familial hypercholesterolemia in patients with acute coronary syndromes in the
Arabian gulf. J Clin Lipidol. 2018;12(3):685-92. https://doi.org/10.1016/j.jacl.2 018.02.003.

26. Rallidis LS, Kosmas N, Tsirebolos G, Rallidi M, Kiouri E, Kalpakos D. Prevalence of heterozygous familial hypercholesterolemia and combined hyperlipidemia phenotype in very young survivors of myocardial infarction and their association with the severity of atheromatous burden. J Clin Lipidol. 2019;13(3):502-8. https://doi.org/10.1016/j.jacl.2019.02.007.

27. Gensini GG. A more meaningful scoring system for determining the severity of coronary heart disease. Am J Cardiol. 1983;51(3):606. https://doi.org/10.1 016/50002-9149(83)80105-2.

28. Harrington RA. Targeting inflammation in coronary artery disease. N Engl J Med. 2017;377(12):1197-8. https://doi.org/10.1056/NEJMe1709904.

29. Nissen SE, Tuzcu EM, Schoenhagen P, Crowe T, Sasiela WJ, Tsai J, et al. Statin therapy, LDL cholesterol, C-reactive protein, and coronary artery disease. N Engl J Med. 2005:352(1):29-38. https://doi.org/10.1056/NEJMoa 042000.

30. Sharma SK, Bolduan RW, Patel MR, Martinsen BJ, Azemi T, Giugliano G, et al. Impact of calcification on percutaneous coronary intervention: MACE-trial 1year results. Catheter Cardiovasc Interv. 2019;94(2):187-94. https://doi.org/1 $0.1002 / \mathrm{ccd} .28099$.

31. Burzotta F, Annone U, Paraggio L, D'Ascenzo F, Biondi-Zoccai G, Aurigemma $C$, et al. Clinical outcome after percutaneous coronary intervention with drug-eluting stent in bifurcation and nonbifurcation lesions: a meta-analysis of 23981 patients. Coron Artery Dis. 2020;31(5):438-45. https://doi.org/10.1 097/MCA.0000000000000847.

32. Danchin N, Farnier M, Zeller M, Puymirat E, Cottin $\mathrm{Y}$, Belle L, et al. Long-term outcomes after acute myocardial infarction in patients with familial hypercholesterolemia: the French registry of acute ST-elevation and non-STelevation myocardial infarction program. J Clin Lipidol. 2020;14(3):352-60. https://doi.org/10.1016/j.jacl.2020.03.008.

33. Khoury E, Brisson D, Roy N, Tremblay G, Gaudet D. Identifying markers of cardiovascular event-free survival in familial hypercholesterolemia. J Clin Med. 2021:10:64

34. Sabouret P, Farnier M, Puymirat E. PCSK9 inhibitors: what place in the management of dyslipidemia? Presse Med. 2019;48(3):227-37. https://doi. org/10.1016/j.lpm.2019.01.009.

35. Gragnano F, Natale F, Concilio C, Fimiani F, Cesaro A, Sperlongano S, et al, Adherence to proprotein convertase subtilisin/kexin 9 inhibitors in high cardiovascular risk patients: an Italian single-center experience. J Cardiovasc Med (Hagerstown). 2018;19(2):75-7. https://doi.org/10.2459/JCM. 0000000000000611

36. Bansilal S, Castellano JM, Garrido E, Wei HG, Freeman A, Spettell C, et al. Assessing the impact of medication adherence on long-term cardiovascular outcomes. J Am Coll Cardiol. 2016;68(8):789-801. https://doi.org/10.1016/j.ja cc.2016.06.005.

37. Kitahara H, Nakayama T, Fujimoto Y, Kobayashi Y. Association between Achilles tendon xanthoma and severity of coronary artery disease in patients undergoing percutaneous coronary intervention. J Cardiol. 2020; 75(6):654-8. https://doi.org/10.1016/j.jjcc.2020.01.002.

38. Hashimoto T, Minami $Y$, Kakizaki R, Nemoto T, Fujiyoshi $K$, Meguro $K$, et al. Achilles tendon thickening is associated with disease severity and plaque vulnerability in patients with coronary artery disease. J Clin Lipidol. 2019; 13(1):194-200. https://doi.org/10.1016/j.jacl.2018.10.007.

39. Sabatel-Pérez F, Sánchez-Prieto J, Becerra-Muñoz VM, Alonso-Briales JH, Mata P, Rodríguez-Padial L. Improving familial hypercholesterolemia index case detection : sequential Actice screening from centralized analytical data. J Clin Med. 2021;10(4):749. https://doi.org/10.3390/jcm10040749.

\section{Publisher's Note}

Springer Nature remains neutral with regard to jurisdictional claims in published maps and institutional affiliations. 